\title{
De NederLANDSE CASUS: Een POLITIEK GEVECHT OM DE GRONDWETSHERZIENING
}

\author{
Dr Jan Pelle Erasmus Univeristeit Rotterdam
}

\section{Inleiding}

Zonder een stevige empirische grondslag is wetenschappelijke kennis over het ontstaan van grondwetten in de nationale en internationale context te vergelijken met theoretisch drijfzand. Een wetenschappelijk verhaal moet zowel theoretisch als empirisch zijn. Daarom zal in dit artikel de politieke geschiedenis van Hoofdstuk 1 van de Nederlandse Grondwet van 1983, getiteld Grondrechten, worden gepresenteerd als een theoretisch relevante casus.

De Nederlandse casus demonstreert in de eerste plaats de langdurige politieke strijd die geleid heeft tot de Grondwet van 1983, in het bijzonder de catalogus van klassieke en sociale grondrechten (Hoofdstuk 1 van de Grondwet van 1983). Het theoretische perspectief van wetenschappelijke interventie, in dit geval de staatsrechtswetenschap, blijkt van belang te zijn met betrekking tot kennis over het ontstaan van grondwetten.

Daarnaast toont de Nederlandse casus ook hoe de wisselwerking tussen de nationale en de internationale context vorm heeft gekregen tijdens de strijd om Hoofdstuk 1 van de Grondwet van 1983. Een overwegend indentieke habitus van staatsrechtswetenschappelijke interventie was kenmerkend voor alle relevante politieke actoren op het nationale niveau. Hoe werden deze betrokkenen nu beïnvloed door de internationale context? Het artikel sluit af met enkele empirisch-theoretische lessen.

\section{De totstandkoming van Hoofdstuk 1 van de Nederlandse Grondwet van 1983}

De geschreven Nederlandse Grondwet kan een rigide Grondwet genoemd worden. De Grondwet herzien is in Nederland geen sinecure. Zo heeft de wijzigingsprocedure plaats in twee lezingen en moet er bij de tweede lezing een twee-derde meerderheid zijn in beide Kamers van het Parlement (Tweede en Eerste Kamer van de Staten-Generaal) om de 
Nederlandse Grondwet te veranderen. In 1983 werd deze zware politieke klus geklaard. Sindsdien opent de Nederlandse Grondwet met een pontificaal hoofdstuk, getiteld Grondrechten. Hoofdstuk 1 omvat de catalogus van klassieke en sociale grondrechten, van het trotse gelijkheidsbeginsel en het verbod op discriminatie ${ }^{1}$ tot en met de gekoesterde bepalingen over het onderwijs. ${ }^{2}$

De totstandkoming van Hoofdstuk 1 was echter geen operatie in isolatie. Onmiskenbaar voltrok zij zich in de context van een meeromvattend politiek proces: het streven naar een algehele herziening van de Grondwet. Hoe langdurig was nu deze politieke strijd om de grondwetsherziening! Tussen 1945 en 1983 werden op het politieke toneel in Nederland talrijke relevante inititiatieven genomen. Hoofdstuk 1 (Grondrechten) blijkt - achteraf beschouwd - het pronkstuk te zijn van het politieke proces dat leidde tot de Nederlandse Grondwet van 1983: in 23 artikelen kregen de klassieke en sociale grondrechten op systematische wijze een prominente plaats, bestaande grondrechten werden uitgebreid en nieuwe grondrechten zijn opgenomen in de Grondwet. Bovendien voorzag de Nederlandse grondwetgever deze grondrechten in algemene zijn van spraakmakende interpretaties, bijvoorbeeld voor wat betreft de werkingssfeer (de horizontale werking) en de beperkingsmogelijkheden van grondrechten.

Gebaseerd op een variëteit aan historische bronnen vanaf $1945^{3}$ heb ik de totstandkoming van Hoofdstuk 1 van de Nederlandse Grondwet van 1983 gereconstrueerd. Hoe is dit belangrijke hoofdstuk nu tot stand gekomen? Allereerst is het de vraag hoe dit bijzondere politiek-historisch proces moet worden begrepen. Historische waarheid over historische werkelijkheid, zo luidt mijn opvatting, manifesteert zich in een theoretisch standpunt. Zo'n theoretisch standpunt is wat Max Weber ooit noemde een 'Gedankenbild' of 'Idealtypus'. Gebruik makend van de 'Idealtypus' als een analytische constructie zou ik de nadruk willen leggen op de functionele relatie tussen kennis, gezag en macht: wetenschap als macht.

$1 \quad$ A 1 van de Nederlandse Grondwet van 1983.

2 Het politiek kleurrijke a 23 van de Nederlands Grondwet van 1983.

3 Zoals archieven van departementen, politieke partijen en politici, interviews met sleutelfiguren en literatuur. 
Experts (i.c. ambtenaren, leden van staatscommissies, regeringscommissaris, staatsrechtelijke adviseurs, parlementaire fractiespecialisten en ministers) zijn aldus de politieke actoren in de strijd om de Nederlandse Grondwet van 1983. Het politiek proces wordt verbeeld als een machtsstrijd. Wetenschappelijke kennis en wetenschappelijke gezag kunnen in dit machtsspel figureren als vitale hulpbronnen. Door het meer of minder weloverwogen aanwenden van deze hulpbronnen door sommige actoren wordt het (voornemen tot) handelen van één of meer andere actoren getroffen, daar allen dezelfde habitus hebben in dit specifieke veld van menselijk handelen, namelijk de habitus van wetenschappelijke interventie.

Wetenschappelijke interventie betekent meer concreet dat een kleine groep van experts het 'politieke' probleem (i.c. de herziening van de grondwettelijke grondrechten) behandelt als een 'wetenschappelijk' probleem. De deskundigen zijn er aan gewend om het 'probleem' te definiëren, op te lossen of te bediscussiëren binnen de eigen wetenschappelijke discipline. De experts communiceren zo op een 'normale' manier in hun eigen esotherische taal en tonen diep respect voor relevante wetenschappelijke kennis en gezag. Functioneel-rationeel handelen is geïnstitutionaliseerd in deze context. De institutionalisering van wetenschappelijke interventie bevestigt dan de afhankelijkheid ofwel de machtsrelatie tussen 'de gevestigden' (de experts) en 'de buitenstaanders'.

De genoemde historische bronnen zijn in dit theoretische gezichtspunt van 'staatsrechtswetenschap als interventiewetenschap' geïnterpreteerd. Wat kan nu worden geconcludeerd met betrekking tot de totstandkoming van Hoofdstuk 1 van de Nederlandse Grondwet 1983? Drie conclusies kunnen worden gepresenteerd.

\subsection{Staatsrechtswetenschap als interventiewetenschap werd in Nederland geïnstitutionaliseerd ten behoeve van de grondwetherziening}

In 1963 werd in het Nederlandse openbaar bestuur de staatsrechtswetenschap als interventiewetenschap geïnstitutionaliseerd. Het Ministerie van Binnenlandse zaken stelde een gloednieuwe afdeling Grondwetszaken in, bedoeld om de constitutionele expertise te 
bundelen. De ontwerpers van dit idee wensten een 'Wahlverwandschaft' tussen de staatsrechtswetenschap en de politiek om zo de grondwetsherziening voor te bereiden. De afdeling moest een uniek 'wetenschappelijke laboratorium' en een 'kennisbank' worden voor alle constitutionele zaken. Tussen 1963 en 1983 maakte de afdeling Grondwetszaken deze ambitie inderdaad waar.

Naast deze speciale afdeling creëerde de minister van Binnenlandse Zaken ook een informeel 'Hooglerarenberaad'. In het begin van de jaren zestig debatteerden bekende Nederlandse professoren in het staatsrecht regelmatig met rijksambtenaren over de geplande grondwetsherziening. Toonaangevende academische staatsrechtsgeleerden maakten bovendien deel uit van de staatscommissie-Cals/Donner. In de periode 1968-1971 rapporteerde deze staatscommissie aan de regering over de grondwetsherziening. Tenslotte werd D Simons, professor in het staatsrecht, in 1971 benoemd tot regeringscommissaris voor de grondwetsherziening. Tussen 1971 en 1983 was Simons, samen met leden van de afdeling Grondwetszaken, de drijvende kracht achter het proces dat leidde tot de Grondwet van 1983. Zowel binnen als buiten het parlement verwierf hij een indrukwekkende reputatie van expertise.

\subsection{Een overwegend identieke habitus van staatsrechtswetenschappelijke interventie was kenmerkend voor alle personen die betrokken waren bij de totstandkoming van Hoofdstuk 1 sinds de jaren zestig}

Kenmerkend voor de Nederlandse habitus (van staatsrechtswetenschappelijke interventie) in die tijd was zowel de interesse in wetenschappelijke politiek als de hoge achting voor kennis en gezag op het gebied van het staatsrecht. Een staatsrechtsgeleerde had een hoge sociale status in dit specifieke veld van ambtenaren, commissieleden, regeringscommissaris, staatsrechtelijke adviseurs, parlementaire fractiespecialisten en ministers. Bovendien spraken alle betrokkenen dezelfde taal: de wetenschappelijke taal van het staatsrecht. Ze behoorden tot een elite omdat ze de 'correcte' rechtstaal beheersten. 'Problemen' inzake de grondrechten werden zo veelal beschouwd als 'juridisch-technische' problemen en oplossingen en onenigheden werden uitgedrukt in het wetenschappelijke vocabulaire van het 
staatsrecht. Staatsrechtelijke argumentaties telden; de partijpolitieke achtergrond van de actoren of de partijpolitieke samenstelling van een Nederlands coalitiekabinet was zo goed als irrelevant. De experts, relatief beperkt in aantal, waren uitermate geïnteresseerd in de vernieuwing van de grondwettelijke grondrechten. Zij traden met elkaar in debat over de kleinste details. Het kon zelfs gebeuren dat rechtswetenschappelijke debatten in universitaire kring (bijvoorbeeld over de horizontale werking, het systeem van beperkingen, de vrijheid van meningsuiting of rechterlijke toetsing) werden voortgezet op het niveau van politiekambtelijke besluitvorming van de Nederlandse rijksoverheid, en vice versa; het was één debat.

\subsection{Het debat over de vernieuwing van grondrechten in de Grondwet was een politiek debat, ook al werd het exclusief in staatsrechtelijke termen gevoerd}

In het Nederlandse staatsrechtelijke discours manifesteerde het 'politieke' aspect, conceptueel gerelateerd aan macht, zich in teksten zoals de Proeve van een Nieuwe Grondwet uit 1966 (een compleet uitgewerkte nieuwe Grondwet, opgesteld door ambtenaren en bedoeld om een maatschappelijk debat uit te lokken), in rapporten van de staatscommissie-Cals/Donner, in de wetsvoorstellen en in de Memories van Toelichting. Deze teksten drukten in de terminologie van het staatsrecht normatieve politieke standpunten uit: over de aard van een Grondwet en van grondrechten; over de verdeling van bevoegdheden, bijvoorbeeld de bevoegdheid om beperkingen aan te brengen op grondrechten of de bevoegdheid om wetten te toetsen aan de Grondwet; over de grondrechten die burgers toekomen; over rechtswerking van de grondrechten, enzovoort. Deze standpunten hadden betrekking op de 'goede' machtsverhouding tussen de burgers en de staat en dus maakten de auteurs van de bovenvermelde teksten politieke keuzes.

Daarnaast manifesteerde het politieke aspect zich ook in de poging om politieke waarden te realiseren door middel van een grondwetsherziening. Leden van de afdeling Grondwetszaken (Ministerie van Binnenlandse Zaken) maakten deel uit van een wetenschappelijk interventieteam. Zij waren de 'constitutional engineers' in het Nederlandse openbaar bestuur. Ze belichaamden het functionele rationele handelen, maar in de zestiger 
jaren was dit handelen ingebed in een specifieke politieke waarde, namelijk de waarde van massale participatie in het politieke proces. De bovengenoemde Proeve van een Nieuwe Grondwet was hun juridisch-technisch vehicle om een maatschappelijk debat te initiëren over de grondwetsherziening. Meer in het algemeen probeerden alle leden van een bijzondere Nederlandse 'epistemische gemeenschap' (dat wil zeggen alle personen die betrokken waren bij de totstandkoming van Hoofdstuk 1 van de Grondwet) om nobele, maar betwiste politieke waarden te realiseren, zoals participatie, vrijheid, rechtvaardigheid, gelijkheid en solidariteit. Zij werkten aan een nieuwe grondwettelijke catalogus van grondrechten, bij uitstek een politieke waardenbasis verhuld in een juridisch jasje.

Ten derde manifesteerde het 'politieke' zich in de wijze waarop het debat over de vernieuwing van de grondrechten in de Grondwet werd gevoerd. Staatsrechtelijke kennis en staatsrechtelijk gezag vormden vitale hulpbronnen in de politieke strijd om de Nederlandse Grondwet van 1983. Door al dan niet bewust gebruik te maken van deze hulpmiddelen beïnvloedden één of meer actoren het (voornemen tot) handelen van één of meer andere actoren. Het wijzigen van de Nederlandse Grondwet was een argumentatief duel, maar niettemin een strijd om macht. Een (staatsrechterlijk) taalspel is altijd een machtsspel. Om het bekende aforisme van Von Clausewitz te parafraseren: in een epistemische gemeenschap kan menselijk handelen, gedreven door wetenschappelijke interventie, worden beschouwd als de voortzetting van een politiek conflict met andere middelen.

Het theoretische perspectief van staatsrechtwetenschappelijke interventie, zo kan worden geconcludeerd, is een waardevol gezichtspunt om het verhaal over de totstandkoming van Hoofdstuk 1 van de Nederlandse Grondwet van 1983 te vertellen. Staatsrechtswetenschap als interventiewetenschap werd geïnstitutionaliseerd en sinds de zestiger jaren was een overwegend identieke habitus van staatsrechtswetenschappelijke interventie kenmerkend voor alle betrokkenen bij de totstandkoming van Hoofdstuk 1. Door middel van deze habitus van wetenschappelijke interventie konden de leden van een bepaalde epistemische gemeenschap macht uitoefenen. Het theoretische gezichtspunt van wetenschappelijke interventie bleek een vruchtbaar perspectief te zijn om de totstandkoming van Hoofdstuk 1 van de Nederlandse Grondwet van 1983 te reconstrueren. 


\section{De Nederlandse internationale context}

De volgende vraag is hoe deze nationale politieke spelers beïnvloed werden door de internationale context. De beschrijving van het Nederlandse politieke proces (tussen 1945 en 1983) leerde mij dat er niet zoiets bestond als 'de' internationale context in verband met de vernieuwing van de grondrechten. In plaats daarvan waren er (meerdere) 'contexten'. Dat wil zeggen: in de hierboven beschreven Nederlandse casus kunnen vier internationale 'feiten' worden beschouwd als de invulling van 'de' internationale context. Onderscheiden kunnen worden:

(a) de context van de koloniale erfenis;

(b) de context van gepercipieerd internationaal gevaar;

(c) de context van internationaal recht en

(d) de context van de elders toegepaste organisatie van een grondwetsherziening.

Deze internationale `feiten' bleken politiek relevant, hoewel niet altijd in dezelfde mate.

Wat bedoel ik precies met politiek relevant? In relatie tot het ontwerpen van Grondwetten moeten deze internationale 'feiten' worden beschouwd worden als 'politieke hulpbronnen'. Een politieke hulpbron is een middel waarmee een (nationale) actor zowel zijn eigen handelen kan rechtvaardigen als het gedrag van andere nationale actoren kan beïnvloeden. Door internationale 'feiten' te gebruiken kunnen één of meer nationale actoren het (voornemen tot) handelen van één of meer andere nationale actoren beïnvloeden. In dat geval gebruiken degenen die invloed willen uitoefenen de internationale context als het politiek kapitaal om de anderen te overtuigen, uit te dagen, te bedreigen of te inspireren.

In de Nederlandse casus werden vier internationale 'feiten' gevonden. Laat me de Nederlandse internationale contexten te illustreren. 


\section{De context van koloniale erfenis}

Nederland heeft een koloniaal verleden. Nederlandse burgers woonden niet enkel in het Europese vaderland, maar ook in landen als Indonesië, Suriname en een aantal Caribische eilanden. Heeft het Europese vaderland dan de verplichting om haar grenzen open te stellen voor alle Nederlandse burgers? Hebben alle Nederlandse burgers (de Nederlandse burgers van Suriname, de Antillen, enzovoort inbegrepen) dan het onbeperkte grondwettelijke grondrecht op toelating tot het Europees grondgebied? Of geldt voor hen slechts een beperkt constitutioneel recht?

Tussen 1945 en 1983 waren de politieke actoren (betrokken bij de herziening van de Nederlandse Grondwet) het hierover oneens, soms zelfs zeer grondig oneens. Sommigen zeiden dat we de gevolgen van onze koloniale erfenis moesten aanvaarden. Wat hen betrof zouden in de herziene Nederlandse Grondwet (de vigerende Grondwet zweeg over het recht op toelating) alle Nederlandse burgers toegelaten worden tot Nederland. Anderen daarentegen zeiden te vrezen voor de sociale en juridische problemen van onbeperkte toelating. In het beste geval zou er sprake kunnen zijn van een beperkt grondrecht: enkel Nederlandse burgers, territoriaal behorend tot Nederland, zouden toegelaten worden. In de beslissende fase van de besluitvorming besloot WF de Gaay Fortman (Minister van Binnenlandse Zaken) in de jaren zeventig om terug te vallen op een reeds bestaande bepaling in de Nederlandse Grondwet. Deze bepaling luidde: "De wet regelt de toelating en de uitzetting van vreemdelingen". Volgens de minister maakte deze bepaling het reeds mogelijk om een toelatingsregeling in te voeren. Zijn interpretatie werd tenslotte aanvaard. Daarom rept de Nederlandse Grondwet van 1983 met geen woord over het onbeperkte of beperkte grondrecht op toelating voor Nederlandse burgers.

In de Nederlandse context van koloniale erfenis ontstond een politiek conflict over de noodzaak en de inhoud van het grondwettelijke grondrecht op toelating. Dit conflict heeft echter niet geleid tot een tekstuele verandering van de Nederlandse Grondwet. 


\section{De context van gepercipieerd internationaal gevaar}

De communistische machtsovername van het bewind in Praag (1948) had een schokkend internationaal effect. Volgens een Nederlandse politieke meerderheid zou het communisme krachtig moeten worden bestreden. In de jaren vijftig betekende de Nederlandse 'koude oorlog' tegen het communistische 'rode gevaar' onder meer de uitsluiting van de Communistische Partij Nederland (CPN) van de staatscommissie-Van Schaik (in de periode 1950-1954 rapporteerde deze staatscommissie aan de regering over de grondwetherziening). De Nederlandse Ministerraad besloot in 1950 dat het misbruik van de grondrechten (de Raad bedoelde 'misbruik' door communisten) besproken moest worden in de in te stellen staatscommissie-Van Schaik en dus waren alle politieke partijen welkom in de commissie behalve de CPN.

De bestrijding van het communisme betekende in de jaren vijftig ook de controversiële poging (hoofdzakelijk geïnitieerd door de machtige Nederlandse Katholieke Volkspartij) om bijzondere beperkingen op de persvrijheid aan te brengen. CPM Romme (de politieke leider van de Nederlandse Katholieken) riep op tot een morele kruistocht tegen het communistisch kwaad en beweerde dat de communisten de persvrijheid (zoals vastgelegd in de Nederlandse Grondwet) gebruikten om het democratische systeem te vernietigen. De context van gepercipieerd internationaal gevaar veroorzaakte een bekend politiek dilemma: moeten we de democratie beschermen met ondemocratische middelen? Romme en anderen dachten dat dit moest. Een democratisch volk diende voorbereid te zijn op een oorlog. De herziene Nederlandse Grondwet (in tegenstelling tot de geldende Grondwet) zou daarom de mogelijkheid moeten bieden om een tijdelijk verbod van (communistische) publicaties op te leggen. Een wijziging van de Nederlandse Grondwet, sommigen spraken over een 'versterking' van de Grondwet, werd blijkbaar beschouwd als een belangrijk middel om het communisme te bestrijden. De poging om de grondwettelijke persvrijheid 'aan te passen' werd heftig bediscussieerd, maar mislukte uiteindelijk. De regering besloot om vast te houden aan het geldende staatsrecht. Het Parlement aanvaardde de opvatting dat de beste remedie tegen veronderstelde ondemocratische krachten is om vertrouwen te blijven hebben in de democratie, in dit geval uitgewerkt in de grondwettelijk gegarandeerde persvrijheid. 


\section{De context van internationaal recht}

De meest invloedrijke internationale context met betrekking tot de totstandkoming van Hoofdstuk 1 van de Nederlandse Grondwet was de context van het internationale recht. Na de verschrikkingen van de Tweede Wereldoorlog werden de mensenrechten een politieke kwestie van het hoogste mondiale belang. Deze groeiende aandacht culmineerde in internationale juridische teksten, zoals de Universele Verklaring van de Rechten van de Mens (1948), de Europese Conventie voor de bescherming van de Mensenrechten en de Fundamentele Vrijheden (1950) en de bijbehorende protocollen, het Europees Sociaal Handvest (1961), het Internationaal Verdrag inzake Burgerrechten en Politieke Rechten (1966) en het Internationaal Verdrag inzake Economische, Sociale en Culturele Rechten (1966).

Deze internationale ontwikkelingen lokten fundamentele vragen uit in het naoorlogse debat over de Nederlandse Grondwetherziening: maken de bovengenoemde juridische teksten de Nederlandse Grondwet overbodig? Wat zou de relatie moeten zijn tussen internationaal recht en de grondrechten in de nationale (Nederlandse) Grondwet? Hoe moeten de grondwettelijke grondrechten worden aangepast aan de internationale juridische ontwikkelingen?

Over het algemeen gesproken bepaalde de internationale juridische context de politieke agenda in de discussies over de manier waarop de grondrechten in de Nederlandse Grondwet moesten worden geanalyseerd en vernieuwd. Deze context was een alom tegenwoordig referentiekader. Het stelde de politieke actoren bijvoorbeeld in staat om de rapporten van de twee staatscommissies te beoordelen en om nieuwe Nederlandse grondwettelijke grondrechten te introduceren (zoals het verbod op discriminatie en de sociale grondrechten), ${ }^{4}$ of om eigen voorstellen te rechtvaardigen, zoals het plan om rechterlijke toetsing in te voeren. Meerdere pogingen zijn ondernomen om de bevoegdheid tot rechterlijke toetsing in

$4 \quad$ Respectievelijk a 1 en de an 18-23 van de Nederlandse Grondwet van 1983. 
de Nederlandse Grondwet vast te leggen, maar tevergeefs. De clausule 'De rechter treedt niet in de beoordeling van de grondwettigheid van wetten en verdragen' is nog steeds opgenomen in de Nederlandse Grondwet. ${ }^{5}$ In dit verband is een paradoxale situatie in Nederland ontstaan. Dankzij internationale juridische ontwikkelingen erkent de Nederlandse Grondwet sinds 1953 het primaat van het internationaal recht. Het huidige artikel 94 van de Nederlandse Grondwet van 1983 luidt aldus:

Binnen het Koninkrijk geldende wettelijke voorschriften vinden geen toepassing, indien deze toepassing niet verenigbaar is met een ieder verbindende bepalingen van verdragen en van besluiten van volkenrechtelijke organisaties.

Het gevolg is bijvoorbeeld dat Nederlandse rechters de nationale wetgeving mogen toetsen aan het verbod op discriminatie, vastgelegd in artikel 26 van het Internationaal Verdrag inzake Burgerrechten en Politieke Rechten, maar dat zij dit niet mogen doen aan de vergelijkbare voorziening in Artikel 1 van de Nederlandse Grondwet.6

\section{De context van de elders toegepaste organisatie van een grondwetsherziening}

Hoe moet een grondwetsherziening worden georganiseerd? In de jaren zestig vonden de Nederlandse ambtenaren van het ministerie van Binnenlandse Zaken twee voorbeelden in het buitenland. Het idee van de eerder beschreven institutionalisering van het staatsrecht als interventiewetenschap (door een geheel nieuwe afdeling Grondwetszaken en door het hooglerarenberaad) werd ontleend an de Oostenrijkse 'Verfassungsdienst des Bundeskanzlerants'. (Deze 'Verfassungsdienst' werd ingesteld in 1918. Bekende geleerden zoals Kelsen en Ermacora waren met deze dienst verbonden.)

Het tweede voorbeeld werd gevonden in Joegoslavië. In 1962-1963 was in dat land de voorgenomen nieuwe Grondwet de inzet van een succesvol maatschappelijk debat. Nederlandse ambtenaren meenden dat een dergelijk proces van massale politieke participatie

5 A 120. 
ook in Nederland moest worden georganiseerd. Inderdaad kregen zij toestemming om zowel de bovengenoemde Proeve van een Nieuwe Grondwet te publiceren als om een maatschappelijk debat over de Grondwetsherziening te starten.

\section{Besluit}

De politieke strijd die leidde tot de Nederlandse Grondwet van 1983 (Hoofdstuk 1, Grondrechten) is een empirisch-theoretisch relevante casus. Waarom?

\section{Stil spel in de politieke arena}

De Nederlandse casus maakt duidelijk dat de behandeling van een belangrijk politiek probleem (de herziening van de grondwettelijke grondrechten) en het maken van fundamenteel vernieuwende politieke keuzes (Hoofdstuk 1 als het pronkstuk van de Grondwetherziening) verrassenderwijs kunnen plaatsvinden door middel van - wat ik zou willen noemen - een stil spel in de politieke arena. De kunst om een Grondwet te ontwerpen wordt toevertrouwd aan 'constitutional engineers' die het 'politieke' probleem beschouwen als een 'wetenschappelijk' probleem. De experts kunnen natuurlijk van mening verschillen over de oplossingen van dit probleem, maar buiten de epistemische gemeenschap besteedt niemand aandacht aan dit vraagstuk, hoe belangrijk het ook moge zijn. Jammer of niet, maar partijpolitieke ideologische conflicten, electorale belangen of het politieke lot van een coalitiekabinet zijn niet altijd verbonden met het maken van een nieuwe Grondwet.

\section{Technocratisch bewind}

Als in een politiek systeem zoals dat van Nederland leden van een epistemische gemeenschap het politiek slagveld inzake de herziening van de Grondwet kunnen monopoliseren, en als de herziene Grondwet de vrucht is van hun werk, dan is er in feite sprake van een technocratisch bewind in een formeel democratische staat.

6 Kortmann en Bovend'Eert Inleiding op de Nederlandse Grondwet 118. 


\section{Habitus van wetenschappelijke interventie als machtsbron}

Het theoretische gezichtspunt van staatsrechtswetenschappelijke interventie toont hoe macht in een concrete culturele context wordt uitgeoefend. Een kleine groep van experts behandelt het politieke probleem als een staatsrechtswetenschappelijk vraagstuk. Zij zijn gedisciplineerd om problemen in het perspectief van de staatsrechtswetenschap te definiëren, op te lossen of te bediscussiëren. Zo communiceren zij in hun eigen esotherische taal en tonen diep respect voor kennis en gezag op staatsrechtelijk terrein. Alle leden van de epistemische gemeenschap hebben dezelfde habitus in dit specifiek veld van menselijk handelen, namelijk de habitus van staatsrechtswetenschappelijke interventie. Niet door middel van dwang, maar door de habitus van wetenschappelijke interventie kunnen zij macht uitoefenen.

\section{'De' internationale context bestaat niet}

De Nederlandse casus leerde mij dat er niet zoiets bestaat als 'de' internationale context met betrekking tot de herziening van de grondrechten. In plaats daarvan is er:

(a) de context van koloniale erfenis;

(b) de context van gepercipieerd internationaal gevaar;

(c) de context van internationaal recht en

(d) de context van de elders toegepaste organisatie van een grondwetsherziening.

Deze vier internationale 'feiten' kunnen worden beschouwd als de materialisatie van de internationale context.

\section{Internationale contexten blijken politiek relevant te zijn}

Zoals samengevat in figuur 1 kan een tweevoudige politieke relevantie worden onderscheiden. In de eerste plaats veroorzaken internationale contexten politieke issues. 
Deze kunnen betrekking hebben op: politieke theoretische vraagstukken, fundamentele juridische vraagstukken, juridisch-technische vraagstukken of organisatorische vraagstukken. In de tweede plaats kunnen deze contexten (gepercipieerd in issues) een politieke impact hebben, zoals: het veroorzaken van een politiek conflict, het bepalen van de politieke agenda, het vormen van een referentiekader, het initiëren van organisatorische veranderingen of het herschrijven van de tekst van de Grondwet. In mijn opvatting wordt 'politieke relevantie' conceptueel verbonden met 'macht' of 'invloed'. Politiek relevant betekent macht uitoefenen over politieke actoren. In dit opzicht was de context van het internationale recht de meest invloedrijke internationale context in Nederland. De impact van de context van het internationale recht demonstreert hoe krachtig het menselijke handelen in de nationale politieke arena kan worden beïnvloed door een internationale context en hoe uiteenlopend die invloed kan zijn. Als de habitus van staatsrechtswetenschappelijke interventie kenmerkend is voor alle betrokkenen bij de totstandkoming van de Grondwet, dan lijkt het overigens niet zo vreemd dat hun habitus juist doordrongen is van de context van het internationale recht. 


\section{Figuur 1}

Internationale contexten in de politieke geschiedenis van Hoofdstuk 1 van de Nederlandse Grondwet (1945-1983)

\begin{tabular}{|l|l|l|}
\hline Contexten & Issues & Impact \\
\hline Koloniale erfenis & $\begin{array}{l}\text { Heeft het koloniale vaderland de grondwettelijke } \\
\text { verplichting zijn grenzen open te stellen voor } \\
\text { alle burgers? Hebben alle burgers het } \\
\text { grondwettelijke grondrecht op toelating? }\end{array}$ & $\begin{array}{l}\text { Politiek conflict. Geen } \\
\text { tekstuele verandering van } \\
\text { de Grondwet. }\end{array}$ \\
\hline $\begin{array}{l}\text { Gepercipieerd internationaal } \\
\text { gevaar }\end{array}$ & $\begin{array}{l}\text { Moeten we de democratie verdedigen met } \\
\text { ondemocratische middelen? Moet de } \\
\text { grondwettelijke persvrijheid worden angepast? }\end{array}$ & $\begin{array}{l}\text { Politiek conflict. Geen } \\
\text { tekstuele verandering. }\end{array}$ \\
\hline Internationaal recht & $\begin{array}{l}\text { Maken internationale juridische teksten de } \\
\text { Grondwet overbodig? Wat zou het verband } \\
\text { moeten zijn tussen het internationaal recht en de } \\
\text { grondrechten in de nationale Grondwet? Hoe } \\
\text { moeten de grondwettelijke grondrechten worden } \\
\text { aangepast aan de internationale juridische } \\
\text { ontwikkelingen? }\end{array}$ & $\begin{array}{l}\text { Politiek conflict. Het } \\
\text { bepalen van de politieke } \\
\text { agenda. Een altijd } \\
\text { Tekstuele en niet-tekstuele } \\
\text { verandering. }\end{array}$ \\
\hline $\begin{array}{l}\text { De organisatie van de } \\
\text { grondwetsherziening }\end{array}$ & $\begin{array}{l}\text { Hoe moet het politieke proces van een } \\
\text { grondwetswijziging worden georganiseerd? }\end{array}$ & $\begin{array}{l}\text { Een nieuwe afdeling } \\
\text { Grondwetszaken in de } \\
\text { rijksdienst. Het initiëren } \\
\text { van een maatschappelijk } \\
\text { debat over de } \\
\text { grondwetsherziening. }\end{array}$ \\
\hline
\end{tabular}




\title{
5 Bibliographie
}

Kortmann en Bovend'Eert Inleiding op de Nederlandse Grondwet 118

Kortmann CAJM en Bovend'Eert PPT Het Koninkrijk Nederland: een inleiding op de Nederlandse Grondwet (Kluwer Deventer 1993)

\section{Wetgeving}

Nederlandse Grondwet van 1983 (Hfdst 1, Grondrechten

\author{
Afkortinge \\ A - Artikel \\ a - artikel \\ An - Artikelen \\ an - artikelen \\ CPN - Communistische Partij Nederland \\ Hfdst - Hoofdstuk \\ hfdst - hoofdstuk \\ i.c. - in dit geval
}

